\title{
REPERCUSSÃO ESPACIAL DO CIRCUITO FM: AS EMISSORAS CONCESSIONADAS E OS EVENTOS MUSICAIS EM CAMPINAS.
}

- CRISTIANO NUNES ALVES 1

Resumo: Esse artigo busca analisar as dinâmicas socioterritoriais na cidade atual. Para tanto, pretendemos contribuir para 0 entendimento da conformação e da espessura do circuito de rádio FM em Campinas. A cidade desde 0 início das manifestações radiofônicas conta com uma densidade técnica informacional favorável à difusão da musica. 0 circuito FM em Campinas se insere no campo da indústria cultural desde a década de 1970, num processo que demonstra a ligacção direta entre a urbanização e metropolização crescentes no Brasil e 0 adensamento do circuito de rádio difusor de um repertório musical médio. 0 estudo do circuito FM atual a partir de sua programação e eventos musicais indica como o componente musical é atrelado a estratégias verticais de uso do território. Problematizamos a repercussão espacial dos meios de informação de massa e as condições geográficas contemporâneas de vida na cidade, um lugar que abriga densidades técnica, informacional e comunicacional.

Palavras-chave: Uso do Território. Comunicação. Informação. Música. Urbanização.

1. Introdução: O Circuito Sonoro

Atualmente com cerca de 1.200 .000 habitantes, Campinas é a terceira maior cidade do estado de São Paulo-SP. O município e o seu entorno são elos técnico-informacionais intensamente ligados à metrópole paulistana.

A partir da década de 1970, período de crescimento do mercado fonográfico nacional que acompanha a urbanização acelerada do território brasileiro, adensa-se o circuito de rádio FM de
Campinas. Nessa situação as emissoras concessionadas de rádio se tornam elementoschave na divulgação em massa da produção musical. De acordo com a nossa reflexão, é a partir daí que se avoluma "a influência no circuito sonoro", uma importante variável do espaço geográfico contemporâneo ${ }^{2}$.

A dinâmica do circuito sonoro implica o uso de ruas, praças, bares, objetos técnicos de informação - desde rádios até telefones celulares - estúdios 
fonográficos, emissoras de rádio, satélites de informação, lojas de discos, entre outros. Seu movimento engloba o registro material da produção fonográfica, as mediações cotidianas das experiências relacionadas à música e o fluxo informacional envolvido na produção do registro sonoro, nos eventos musicais, nas ações de trabalhadores culturais e no campo de informação embutido.

Segundo Claire (2006, p. 21), ao geógrafo interessa a música e suas localizações, reais e ideais:

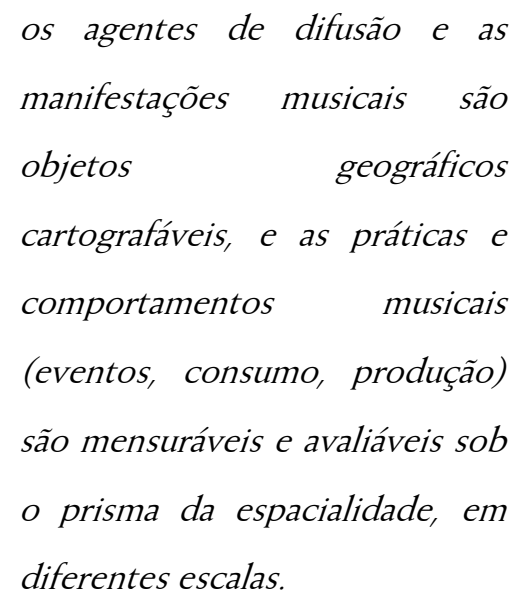

Romagnan (2000) destaca, nesse sentido, a importância do estudo da repartição e da difusão de atividades musicais no território. Para entender o caráter sistêmico da música, seu simbolismo e "as ressonâncias que ela propaga" (Idem, p. 114).

Por sua vez, Carney (2003) apresenta alguns elementos que podem ajudar na busca da comunicação no circuito sonoro na dimensão cotidiana do fato urbano. Na cidade, explica o autor, a relação com a música pode acontecer em situações vividas em lugares distintos, o que confere à cidade um papel central na prática musical.

Para retratar o circuito sonoro em Campinas, esmiuçamos a produção e a difusão em torno do componente musical, variável de um intrincado espaço urbano, pautado na desigualdade socioterritorial. Entendemos que o rádio FM na cidade expõe um dos momentos deste circuito, cada vez mais adensado pelos signos da indústria cultural, invasora dos lugares, e de seus microcircuitos em torno das experiências sonoras.

\section{2-Objetivos}

Nesse artigo, destacamos a radiodifusão FM, uma das formas-conteúdo do atual período, marcado por uma base técnica adequada à transmissão do componente informacional.

Iniciando os trabalhos, apresentamos um breve inventário do circuito das rádios FM concessionadas em Campinas. Em seguida propomos dois pontos para análise: primeiro abordamos o tema da difusão de um repertório médio, idealizado pelos grandes meios de informação. Depois, indagamo-nos sobre a repercussão espacial da FM e a íntima relação dos meios de massa com a produção da consciência no período em curso.

\section{3-Metodologia Utilizada}

Para inventariar o circuito FM em Campinas, além do levantamento bibliográfico 
sobre a temática, realizamos uma série de trabalhos de campo. Reunimos dessa forma um importante "campo de informação primário", resultante de entrevistas com agentes do circuito sonoro e visitas a lugares conformados ou apropriados por esse circuito maior em torno da música. Os relatos, reunidos durante o trabalho de campo, encontram-se no texto acompanhados de um asterisco, que indica pesquisa em fonte primária.

\section{4 - Referencial Teórico - Problematização do} Tema

O adestramento e a imposição musical de práticas consideradas impuras vêm de longa data em território nacional. No Brasil durante o período colonial, num meio em que os conteúdos informacionais acionados e transmitidos se manifestavam necessariamente pela presença humana, foram os padres os primeiros a ensinar música. Nesse contexto, tratava-se de uma maneira de doutrinar os nativos, introjetando neles um som e uma mensagem descendente, pois estranha às suas existências. Por meio da dança e dos sons, afirma Heitor (1945, p. 143) "foi sendo conquistado para Cristo o rebanho selvagem." Iniciava-se, assim, a catequese musical, difundida a partir de colégios jesuítas, alcançando os povoados dos nativos.

Com a radiodifusão, a catequese musical toma outro sentido e se espraia para uma série de lugares. Ortiz (1989) pontua a importância do rádio para a introdução da indústria cultural no país; nesse mesmo sentido Antongiovanni (1999, p. 40) ressalta que a partir de década de 1940 as rádios entram definitivamente na era da publicidade passando a ser "financiadas por agências de publicidade estrangeiras". Caldas (1995) explica que a publicidade fez com que o nível de audiência passasse a ser um dado vital para as emissoras. Como não havia pesquisa de audiência e mercado, a emissora devia ficar conhecida de uma maneira ou de outra, o que implicou o assalto da cidade pelo circuito de rádio.

$\mathrm{Na}$ época, o Ministério da Educação, por meio de Álvaro Salgado, preconizava a importância do veículo como elemento de homogeneização cultural e formação de opinião pública, defendendo o seu uso por meio de zonas irradiadoras de cultura, inseridas num sistema com rádios controladas e oficiais (Salgado, 1941). Nessa ótica o rádio era tido como um meio para conquistar

"os indivíduos analfabetos,
broncos, rudes de nossas
cidades" (Idem, p. 84 )
domesticar os $\quad$ "ritmos
selvagens" como o samba
"tentemos, devagarinho torná-lo
mais educado e social" (...) "não
repudiemos esse nosso irmão
pelos defeitos que contém"

(Ibidem, p. 86).

Goldmann (1972) pondera que a atividade cotidiana, nascedouro e abrigo da consciência, alicerce secular da vida cultural, encontra-se ameaçada pela evolução contemporânea das 
sociedades industriais. Presenciamos a fenômeno esquizofônico, dispõe de uma base "desculturalização pela desorganização dos técnica adequada à disseminação do componente receptores" (Idem, p. 26) a partir das ações de informacional (MARIANO, 1972; GEIGER, enfraquecimento desenvolvidas pelos meios de 1963). Todavia, apenas na década de 1990 definemassa, afirma o autor. Para analisar o se mais claramente o processo de influência dos enquadramento em torno do circuito sonoro grandes meios de informação sobre o circuito campineiro levamos também em consideração os pressupostos de Harvey (1992) sobre a importância de se compreender a divisão técnica e territorial do trabalho presente na produção cultural, um processo de "formação de juízos estéticos mediante um sistema organizado de produção e consumo mediado por divisões do trabalho, exercícios promocionais e arranjos de marketing sofisticados" (Idem, p. 312).

Bem além da formatação, a força do circuito de arte é inegável. Todavia, não apenas o conteúdo sonoro pode invalidar uma música, mas outros fatores, tais como a sua superexposição. Desse modo, ao invés de nos incitar, a paisagem sonora nos paralisa em nosso movimento, reeditado seja nas buzinas padronizadas ou nos sons previsíveis do circuito de rádio FM: anestesiam-nos de novas possibilidades para o território usado, tiram-nos também as sensações.

\section{5-Desenvolvimento do Trabalho}

\section{1 - Espessura informacional em Campinas: o}

\section{Circuito de Rádio FM}

Os processos relacionados à temática indicam que Campinas, desde a chegada do 
Campinas abriga, atualmente, dezesseis emissoras concessionadas, ligadas a 12 grupos de informação, exceto a Rádio Educativa, pertencente à Prefeitura Municipal. Dez emissoras operam em rede e seis transmitem conteúdos a partir de Campinas, município de considerável densidade de sinais de rádio FM. Além da Educativa, direcionada ao segmento adulto, outras cinco programações são produzidas localmente: Laser, Cidade e Líder atuam no segmento popular, enquanto Educadora e 89 FM são direcionadas ao público jovem.

\section{2 - O Circuito FM campineiro e a Repercussão} Espacial das atividades Informacionais

\section{2. 1 - O repertório médio na programação do circuito FM atual: repercussão espacial das atividades informacionais}

O entendimento da repercussão espacial do circuito FM e de toda a sua programação impõe o estudo da relação entre as emissoras o os eventos musicais em Campinas. No Quadro 1 procuramos expor alguns elementos que ponham em relação a um só tempo a programação musical (conteúdos) e seus desdobramentos espaciais mais diretos, ligados sobretudo ao lazer em Campinas e no seu entorno.

Schafer (1997 [1977]) adverte que a maciça presença do rádio causa um grande contraste com os ritmos da vida. Para o autor, antes as paredes isolavam os sons, mas hoje são os sons que servem para isolar, tornando-se a radiodifusão uma continua parede sonora.
No circuito FM de Campinas praticamente não há abertura para a produção local. A adoção do repertório médio implica a vinculação de músicas "estouradas nas paradas" com o predomínio da prática do jabá (propina no rádio), o que, entre outros, dificulta a inserção de artistas locais, ainda que reproduzam o repertório padrão de um determinado segmento.

No exame do circuito de FM, depara-se com a música que nos ata ao presente e faz com que o passado sempre retorne: músicas escolhidas por critérios não musicais dão $\mathrm{o}$ tom. $\mathrm{A}$ programação se reduz quase que totalmente aos sons que exprimem a tendência à informatização do conteúdo musical: "tudo virará o pop", ressaltamos.

\section{2. 2 - $\mathrm{O}$ circuito $\mathrm{FM}$ e os eventos musicais:}

\section{território e lazer sonoro em Campinas}

A homogeneização entre as emissoras, a diversificação de seus produtos e serviços e a predominância das "paradas de sucesso" vão ao encontro ao proposto por Corrêa (1997, p. 70), segundo o qual "um mesmo disco é executado de diversos modos, simultaneamente, em inúmeros canais de rádio". Adicionamos ao pontuado pelo autor que um disco pode ser executado ainda em inúmeros eventos e situações nos quais o repertório médio persiste, muitas das quais orquestradas justamente pelas emissoras concessionadas.

Os próprios trabalhos sobre o rádio ensinam "a receita de bolo", que não se restringe à música em si, mas se encadeia na busca da 
programação homogênea. Algo evidente no trecho a seguir retirado de um guia de produção de rádio:

\section{Uma abertura harmoniosa ou rítmica, bastante conhecida e andamento ligeiro, e com uma breve fala de introdução, proporcionará um bom começo com o qual o ouvinte em geral poderá identificar-se. Em seguida, um número musical mais lento, e daí por diante." (Mcleish, 1999, p. 135).}

Os eventos sonoros e "artísticos" ligados às emissoras de rádio se estendem por toda a cidade: desde shows com artistas das paradas de sucesso a bandas cover que toquem esses mesmos sucessos.

No caso de eventos musicais em Campinas, a inserção dos artistas divulgados na programação e nas paradas musicais do circuito FM é praticamente uma regra, e não raro o artista chega à cidade liderando as paradas. Os casos são inúmeros.

Na Radio 89 FM o critério para que uma banda local tenha abertura na programação, contam-nos os programadores, é a participação em algum desses eventos, entre outros. Esse foi o caso da banda Rastaclone, que teve uma de suas músicas inserida na programação certa época antes de um show patrocinado pela rádio. A música fez parte de uma promoção que sorteou um videogame para as pessoas que a pediram.

Quando um sucesso "estoura", as rádios "brigam para ter o show", pois é nesse curto intervalo de tempo em que o artista e seu hit estão em exposição massiva que se pode tirar maior proveito da onda e ter um maior retorno financeiro. Seja com um trio elétrico ou numa casa de show lotada, organizando, patrocinando ou colaborando, as emissoras de rádio movimentam por vezes toda uma cidade em torno de eventos pautados nas paradas de sucesso.

No caso das emissoras do segmento popular, em geral, esses eventos ocorrem em locais que possam reunir grande quantidade de pessoas, a partir de maciça divulgação: aqui a concessão de um canal utilizado para divulgar a própria mercadoria, no caso o evento musical, "exponencializa" o alcance junto à população da cidade. Emissoras como a Educadora (Campinas), Vox e 88 FM (Americana), ou ainda a Cidade (Campinas), há quase duas décadas, não poupam esforços nesse sentido.

Os eventos de grande porte consistem geralmente em shows realizados em locais públicos no formato de festivais com diversas atrações num mosaico que lembra o playlist, a "cara da emissora", e que envolve uma maior rede de divulgação. O receituário para introjetar o "clima para a festa", por meio da criação de uma psicosfera em torno do fetiche do grande sucesso, compreende anúncios na mídia impressa, outdoors, cartazes, ações promocionais, além da própria rádio divulgando os eventos por meio de spots e chamadas. Soma-se a isso a execução redobrada da música de trabalho do artista que tocará no show e nessa época subirá nas paradas de sucesso da emissora. 
O trecho abaixo se refere ao evento organizado pela Rádio Educadora na ocasião de seu aniversário de 60 anos e mostra que o circuito em torno dos grandes eventos ligados às emissoras de rádio acompanha o processo de segmentação desde a década de 1990:

Um grande show popular - com artistas do primeiro time da música popular brasileira - está marcado para o dia 30 de novembro, no Convívio da Rua 13 de maio. Na noite do mesmo dia 30, os festejos prosseguem na casa noturna Pachá Brasil e devem contar com a presença de João Saad, presidente da Rede Bandeirante, da qual a Educadora faz parte. Mas o ponto alto da data será o lançamento da pedra fundamental da nova emissora, que será construídana Rua Engenheiro Antônio Francisco de Paula Souza, 2801, na saída para Valinhos. Uornal Correio Popular. 31 de dezembro de 1993).

Como dissemos a transmissão em rede, ao ampliar o alcance do conteúdo emitido, entrelaçado e retransmitido a diversos pontos, amplia a base técnica acionada pelo circuito. Os spots que divulgam os eventos musicais patrocinados e/ou organizados por uma rede de rádio, se referem a cada uma das emissoras, em caso de eventos locais. O mesmo não vale para os eventos de grande porte como shows de bandas e artistas de alcance internacional, realizados em geral nas capitais, tais como Scorpions e David Lee Roth, trazidos ao Brasil em 2007 pela Kiss, que divulgou o evento não apenas na capital paulista, mas nos outros pontos de sua rede de colaboradoras no litoral paulista e em Campinas.

Os eventos de médio porte ocorrem em casas noturnas maiores que envolvem um circuito mais espesso e ainda a manipulação das paradas. Em geral dezenas de pontos de venda de ingressos são acionados e um grande número de cartazes toma certos lugares da cidade, caso do distrito de Barão Geraldo, devido a sua concentração de universitários frequentadores em potencial de tais eventos.

Por sua vez os eventos de pequeno porte têm um caráter mais pulverizado e acontecem na forma de ações promocionais ou ainda de eventos periódicos em bares e clubes menores com as chamadas noites regulares da programação das casas noturnas.

Em sua operação, a Antena 1 firma parcerias via departamento comercial com produtores de eventos, "se alguém vai trazer os artistas nós anunciamos, mas não organizamos o evento", explica Déborah*, funcionária da Rede em Campinas. Opção semelhante é a da Rede Jovem Pan que organiza eventos de médio e pequeno porte em especial nas cidades do entorno campineiro.

O diretor da rede CBS em Campinas, Rogério Carbone*, nos disse que a Rádio Escalla 
transmite "sucessos no estilo Antena 1" em busca do público $\mathrm{A}$ e $\mathrm{B}$ e foca seus eventos em teatros e outros "locais mais elitizados", diversificando seus serviços para além das atrações musicais.

$\mathrm{O}$ caso da rádio Kiss nos indica a sinergia entre a programação e os eventos musicais de pequeno porte. As músicas que compõem a grade chegam através do diretor artístico de rede. A direção local pode sugerir inclusões no play-list de músicas ou artistas em destaque, por exemplo, no Delta Bar, local em que tocam bandas do chamado "classic rock". Trata-se das bandas cover, que reproduzem o repertório da rádio. As versões não são bem vindas, o que importa é se aproximar do original gravado; "nós podemos sugerir apenas algo que está tocando na região: exemplo, se está tocando muito Led Zeppelin no Delta, nós acionamos a programação" assevera Rogério Carbone. Ainda quanto aos eventos ligados à Kiss, como o seu alcance compreende a capital paulista, a estratégia local adotada, a exemplo de Campinas, consiste na vazão do repertório da rádio em um bar com música ao vivo: o Morisson Rock Bar, na Vila Madalena, que abriga três vezes por semana o

\section{Kiss In Concert.}

Percebe-se que a impossibilidade de elaboração da programação por parte da emissora local desaparece quando o mote é prever retoques de acordo com a demanda de um circuito enquadrado e dinamizador de um rico capital humano-informativo, constituídos por excelentes músicos que deslocam seu potencial da criação para a mera reprodução.

Operando com 10 mil watts de potência e um raio de 100 quilômetros atingidos por sua difusão, a Rádio Educadora é hoje conhecida por ser a rádio da "invasão pop" recheada de sucessos. Sob a coordenação artística de Fábio Granger, a emissora transmite aos domingos o programa $O n$ The Rocks com brecha para artistas iniciantes. Em torno do programa organiza-se o Festival de Rock "A Vez do Brasil", realizado pela primeira vez em 2003 no Parque Portugal, em Campinas, e reunindo 40 bandas de estilos variados do trash ao pop rock.

Os repertórios padrão, não raro, são os que se destacam em eventos desse tipo, e cada vez mais são os adotados pelos grupos, mesmo os iniciantes no circuito.

De modo geral todas as emissoras do circuito trabalham com promoções. $\mathrm{Na}$ Rede Jovem Pan, as promoções custam a partir de $\mathrm{R} \$$ 2.378,00 para os anunciantes (Tabela 1). A movimentação do Grupo CBS, inclui outros eventos promocionais como a sonorização de postos de gasolina com um videokê que toca o repertório da emissora, entre outros.

\section{Tabela 1}

Chama-nos atenção ainda a pauperização da experiência em detrimento da técnica e da tecnologia que se difunde seja no walkman, inovação que levou ao extremo a privatização da experiência musical, como pondera Carvalho (1999, p. 65), ou nas apresentações sonoras "sem som", com os "teclados de churrascaria": "execuções despersonalizadas, frias (...) frequente, nos restaurantes e casas noturnas, o esquema insólito, impensável há menos de trinta anos atrás, 
de uma pessoa, acompanhada de um teclado, cantar o repertório popular eliminando quase todas as sutilezas da composição."

Tais execuções se difundem em locais de lazer da Região e ao que parece por vários outros lugares do Brasil: o repertório com os "clássicos do rádio" ou os sucessos do momento.

Outra tendência de destaque no circuito FM é a diversificação do negócio com a venda de projetos e produtos da emissora: "A Jovem Pan, por exemplo, começou a fazer discos, que venderam em seis meses 1,5 milhões de unidades", informa Bianco (1999, p. 199). O volume de títulos de emissoras de rádio permite que nas lojas existam seções apenas para esse tipo de coleção.

\section{6- Considerações Finais}

O circuito FM é hoje, um dos elementos responsáveis pela organização e dispersão do componente informacional na rede urbana. Os círculos materiais e imateriais constituintes do circuito FM em Campinas expõem a hierarquia do complexo de aglomerações urbanas, situação na qual se articulam redes e sistemas difusores de uma rígida racionalidade que veicula determinadas estratégias e valores.
Com o estudo do circuito FM em Campinas observamos como um repertório clichê e uma constante de informações medianas (baseadas em padrões) são impostos como parte eficaz da "catequese musical" na cidade contemporânea. Esse procedimento não se circunscreve apenas à programação, mas repercute espacialmente em produtos, eventos e encontros amarrados em torno da presentificação.

Por meio dos circuitos da indústria cultural, a cultura média (padrão) condiciona o que pode ser dito, encenado, escrito ou gravado. A produção artística se torna apenas manufatura, orientada que é por segmentos de mercado. Uma reunião dos conteúdos previsíveis a partir daí difundidos relacionam-se, como vimos, a uma certa espessura técnica-informacional-normativa criada e criadora de uma psicosfera que confere obediência e rigidez ao cotidiano: "As pessoas não experimentam suas crenças estéticas como meramente arbitrárias e convencionais; sentem que elas são naturais, adequadas e morais" (Becker, 1977, p. 218). A partir de ações de enquadramento, o gosto musical, em especial dos jovens, simplesmente por desconhecimento, ou falta de referência, se torna o mesmo.

\section{NOTAS}

(1) Mestre em Geografia, Universidade Estadual de Campinas, Brasil Artigo elaborado em agosto de 2009. Correio eletrônico Cris7cris7@yahoo.com.br. Endereço: Rua Ângela Signori Grigol, n430, Jardim América, Distrito de Barão Geraldo, Campinas-SP. CEP 13084-405. Telefone (19) 35791506.

(2) Trabalhamos sob a perspectiva de que a existência e o funcionamento de um circuito ganha significado quando abordadas as estratégias políticas no território usado, sinônimo de materialização e acontecer de objetos e ações no espaço geográfico. Para Santos (2004 
[1996], p. 232), "a utilização do território pelo povo cria o espaço" e o território "se chama espaço logo que encarado segundo a sucessão histórica de situações de ocupação efetiva por um povo - inclusive a situação atual - como resultado da ação de um povo, do trabalho de um povo." Smith (1988 [1984], p. 123) nos lembra de que a ideia de produção do espaço significa a formação integrada da consciência e da vida material uma vez que "a produção do espaço também implica na produção do significado, dos conceitos e da consciência do espaço que estão inseparavelmente ligados à sua produção física". O território usado seria a construção unificada de duas demandas locais, todavia decorrentes de uma sociedade mais ampla que o lugar: a tecnosfera, a dimensão dos objetos, e a psicosfera, dimensão ligada ao mundo da ação e das ideias. De acordo com Santos (2004 [1996], p 256): "a tecnosfera se adapta aos mandamentos da produção e do intercâmbio e, desse modo, frequentemente traduz interesses distantes; desde, porém, que se instala, substituindo o meio natural ou o meio técnico que a precedeu" enquanto "A psicosfera, reino das idéias, crenças, paixões e lugar da produção de um sentido, também faz parte desse meio ambiente, desse entorno de vida, fornecendo regras à racionalidade ou estimulando o imaginário".

\section{REFERÊNCIAS} BIBLIOGRÁFICAS

ALVES, Cristiano Nunes. O circuito sonoro: radiodifusão FM e produção fonográfica em Campinas-SP. Campinas: Unicamp, 2008, 161 f. Dissertação (Mestrado) - Departamento de Geografia do Instituto de Geociências da Universidade Estadual de Campinas, Campinas, 2008.

ANTONGIOVANNI, Lídia. O meio técnico-cientificoinformacional brasileiro: a publicidade como um vetor das modernizações. São Paulo, USP, 1999, 133 f. Dissertação (Mestrado)

- Departamento de Geografia da Faculdade de Filosofia Letras e Ciências Humanas, Universidade de São Paulo, São Paulo, 1999.

CALDAS, Waldenir. Luz néon: canção e cultura na cidade. São Paulo: SESC, 1995. $157 \mathrm{p}$

CARNEY, George. O. Música e lugar. In: CORREAA, Roberto Lobato; ROSENDAHL, Zeny. Literatura, música e espaço. Rio de Janeiro: EdUERJ, 2007

CARVALHO, José Jorge. Transformações da sensibilidade musica contemporânea. Horizontes Antropológicos, p. 56-89, 1999.

CLAIRE, Guiu. Géographie et musique: état des lieux. Une proposition de synthèse. Geógraphie et Cultures, Paris, n. 59, p. 7 26, 2006.
CÓDIGO BRASILEIRO DE TELECOMUNICAÇÕES. Lei 4.117 de 27 de agosto de 1962

CORRÊA, Tupã Gomes. Mercado de Música: disco e alienação. São Paulo: Expert, 1987. 104 p

GEIGER, Pedro Pinchas. Evolução da rede urbana brasileira. Rio de Janeiro: INEP, 1963. $459 \mathrm{p}$

GOLDMANN, Lucien. A criação cultural na sociedade moderna. São Paulo: Difel, 1972. 118 p.

HARVEY, David. Condição pós-moderna. São Paulo: Edições Loyola, 1992.

HEITOR, Luis. Música e catequese. Cultura Política, n. 40, p. 140148,1945

MAGNONI, Antônio (et all). O rádio digital avança no interior de São Paulo. In: BIANCO, Nélia R. Del; MOREIRA, Sônia Virginia (org). Rádio no Brasil: tendências e perspectivas. Rio de Janeiro/Distrito Federal: UERJ/UNB, 1999.

MARIANO, Júlio. História da imprensa em Campinas. Campinas: Massaioli, 1972. 133 p.

ORTIZ, Renato. A moderna tradição brasileira. São Paulo: Brasiliense, 1989. $222 \mathrm{p}$

ROMAGNAN, Jean-Marie. La musique: un terrain nouveau pour les géographes. Géographie et cultures, Paris, n. 36, p. 107-126, 2000.

SALGADO, Álvaro. Radiodifusão fator social. Revista Cultura Política. Rio de Janeiro, ano 1, n. 6, p. 79-93, 1941

SANTOS, Milton. A natureza do espaço: técnica e tempo, razão e emoção. São Paulo: Hucitec, 2004 [1996]. 384 p.

SCHAFER. R. Murray. A afinação do mundo - uma exploração pioneira pela história passada e pelo atual estado do mais negligenciado aspecto do nosso ambiente: a paisagem sonora. São Paulo: Unesp, 1997 [1977]. 381 p.

SMITH, Neil. Desenvolvimento desigual: natureza, capital e a produção do espaço. Rio de Janeiro: Bertrand Brasil, 1988 [1984]. 250 p.

\section{IMPACT OF SPACE FM CIRCUIT: THE BROADCASTING patron and MUSICAL EVENTS IN CAMPINAS}

Abstract: This paper examines the socio-territorial dynamics in the city today. For this reason, we are looking forward to contribute to the understanding of the formation and the thickness of the circuit of radio FM in Campinas. Since the beginnings of the squizophonics manifestations, this city exhibits technical-informational densities that supports the diffusion of the music. The circuit FM in Campinas falls in the field of cultural industry since the decade of 1970 , and has been expanding in the process of relation between the urbanization and metropolis growing in Brazil and the enlargement of the radio circuit that diffuses a standard repertory. The study of 
the FM circuit - programmation and musical events - exhibits how the music spacialization happens coupled with the strategies of vertical use of the territory. We analyzed the spacial repercussion of the mass-media and the geographical conditions of contemporary life in the city as a place that houses technical, informational and communicational densities.

Key words: Use of the Territory. Communication. Information. Music. Urbanization.

\section{Quadro 1}

\section{Gêneros musicais, segmentos de mercado e repercussão espacial do circuito FM de Campinas}

\begin{tabular}{|c|c|c|}
\hline $\begin{array}{l}\text { Empresa } \\
\text { Rede } \\
\text { Proprietário }\end{array}$ & $\begin{array}{l}\text { Emissora } \\
\text { Frequência Mhz }\end{array}$ & $\begin{array}{l}\text { Programação e eventos musicais } \\
\text { (Entre aspas o discurso das emissoras) }\end{array}$ \\
\hline \multirow{3}{*}{$\begin{array}{l}\text { Grupo } \\
\text { Cidade-Laser } \\
\text { (Odilon Garcia) }\end{array}$} & $\begin{array}{l}\text { CIDADE } \\
92.5\end{array}$ & $\begin{array}{l}\text { Programação: } \\
\text { - As emissoras Cidade e Laser têm em comum o fato de suas } \\
\text { programações musicais serem compostas por "sucessos" do } \\
\text { formato popularesco: pagode, axé, pop nacional e internacional, e } \\
\text { sertanejo classe A. } \\
\text { - De acordo com as pesquisas de opinião a Cidade e a Laser mantêm } \\
\text { hoje, respectivamente a } 2^{\circ} \text { e a } 3^{\circ} \text { posições de audiência em } \\
\text { Campinas, somando cerca de } 30 \text { mil ouvintes por minuto em média, } \\
\text { de segunda a sábado das } 07 \text { às } 18 \text { horas. } \\
\text { - Abertura para produção local mediante jabá. } \\
\text { Eventos musicais: }\end{array}$ \\
\hline & LASER 93.3 & $\begin{array}{l}\text { - O grupo organiza eventos musicais como o "Balancidade" no } \\
\text { recinto público do Taquaral, que chega a reunir } 70 \text { mil pessoas em } \\
\text { shows com os artistas das paradas de sucesso das rádios Cidade e } \\
\text { Laser. }\end{array}$ \\
\hline & MIX 97.5 & $\begin{array}{l}\text { - Programação: pop rock e pop. } \\
\text { - Não organiza, nem divulga eventos musicais em Campinas. }\end{array}$ \\
\hline
\end{tabular}




\begin{tabular}{|c|c|c|}
\hline $\begin{array}{l}\text { Grupo } \\
\text { Comunicações } \\
\text { Brasil SAT }\end{array}$ & $\begin{array}{l}\text { KISS FM } \\
107.9 \\
\text { TUPI } 96.5 \\
\text { SCALLA } \\
96.9\end{array}$ & $\begin{array}{l}\text { - Programação elaborada em São Paulo - sem abertura para } \\
\text { produção local. } \\
\text { - Kiss: clássicos do rock } \\
\text { - Scalla: pop nacional e internacional. } \\
\text { - Tupi: sertanejo } \\
\text { Eventos musicais e outros } \\
\text { - Equipe de promoção terceirizada } \\
\text { - Em nome da Kiss organizam-se eventos no Delta Bar, com bandas } \\
\text { cover e os "clássicos do rock", entre outros. } \\
\text { - A Scalla, por sua vez demonstra a relação direta dos eventos } \\
\text { musicais organizados com o público-alvo da programação: promoção } \\
\text { de shows e peças de teatro em "locais de elite" para o seu "público } \\
\text { classe A e B." }\end{array}$ \\
\hline $\begin{array}{l}\text { Grupo Nova - } \\
\text { Rede Central de } \\
\text { Comunicações } \\
\text { (Orestes } \\
\text { Quércia) }\end{array}$ & $\begin{array}{l}\text { NOVA } \\
\text { BRASIL } \\
103.7\end{array}$ & $\begin{array}{l}\text { - Programação: pop nacional e MPB. } \\
\text { - Slogan de "Moderna e Brasileira", sem abertura para a produção } \\
\text { local. } \\
\text { - Não existe relação direta com organização de eventos musicais. } \\
\text { O que há é uma parceria com a direção do Teatro Tim no shopping } \\
\text { center Dom Pedro e a emissora divulga as peças em sua } \\
\text { programação. }\end{array}$ \\
\hline $\begin{array}{l}\text { Rede Aleluia } \\
\text { (arrendada } \\
\text { junto a Natal } \\
\text { Gale) }\end{array}$ & $\begin{array}{l}\text { MORENA } \\
100.3\end{array}$ & $\begin{array}{l}\text { - Programação: gospel e pregações elaboradas pela Rede Aleluia. } \\
\text { - Relação com eventos religiosos organizados pela Igreja Universal do } \\
\text { Reino de Deus, como encontros, congressos, retiros e cultos. }\end{array}$ \\
\hline Grupo Antena 1 & $\begin{array}{l}\text { ANTENA } 1 \\
107.5\end{array}$ & $\begin{array}{l}\text { - Programação: flash backs. } \\
\text { - Elaborada pela Rede Antena 1: sem abertura para a produção local. } \\
\text { - Apenas divulgação de eventos musicais trazidos por outros } \\
\text { produtores: sem vinculação direta do nome da emissora. } \\
\text { - A rádio divulga peças de teatro em Valinhos, Vinhedo e Indaiatuba. }\end{array}$ \\
\hline $\begin{array}{l}\text { Rede } \\
\text { Metropolitana }\end{array}$ & LÍDER 105.5 & $\begin{array}{l}\text { - Programação: Popularesca (pagode, axé, pop nacional e } \\
\text { internacional e sertanejo classe A). } \\
\text { - Grade elaborada em Campinas, porém sem abertura para a } \\
\text { produção local. A adoção do gênero popularesco implica a vinculação } \\
\text { apenas de músicas "estouradas nas paradas" ou a partir do jabá, o } \\
\text { que inviabiliza a inserção de artistas locais, ainda que reproduzam o } \\
\text { repertório padrão do segmento. }\end{array}$ \\
\hline
\end{tabular}




\begin{tabular}{|c|c|c|}
\hline $\begin{array}{l}\text { Grupo } \\
\text { Bandeirantes }\end{array}$ & $\begin{array}{l}\text { EDUCADOR } \\
\text { A } 91.7\end{array}$ & $\begin{array}{l}\text { - Programação: pop, dance, black e rock. } \\
\text { - Grade elaborada em Campinas reproduzindo o repertório dos } \\
\text { "sucessos jovens" alcançando o primeiro lugar de audiência nos } \\
\text { últimos anos. A emissora trabalha com o slogan de "Invasão Pop", } \\
\text { campanha assinada por uma agência de publicidade local que conta } \\
\text { com spot de rádio, anúncio para revista, busdoor, filme, envelopagem, } \\
\text { mídia na rua, camisetas, folders e net marketing. } \\
\text { - Organiza desde eventos musicais de grande porte em recintos } \\
\text { públicos a festa privadas em casas noturnas da cidade. }\end{array}$ \\
\hline $\begin{array}{l}\text { Rede Jovem } \\
\text { Pan }\end{array}$ & $\begin{array}{l}\text { JOVEM PAN } \\
89.9\end{array}$ & $\begin{array}{l}\text { - Programação: pop, dance, black. } \\
\text { - Outro caso de conteúdo formatado via rede, na busca do "público } \\
\text { classe A e B", sem abertura para a produção local. } \\
\text { Eventos musicais } \\
\text { - A emissora tem o Programa "Na Balada Especial", que divulga "os } \\
\text { agitos do final de semana, os points mais quentes desde choperias da } \\
\text { moda até boates em shoppings centers". } \\
\text { - Divulgação de eventos musicais de médio e grande porte, mas sem } \\
\text { vinculação direta do nome da emissora. }\end{array}$ \\
\hline Grupo Alfa & 89 FM 89.3 & $\begin{array}{l}\text { - Programação: pop, black e pop rock } \\
\text { - Grade elaborada na cidade de São Paulo: acordos com gravadoras. } \\
\text { A proposta da emissora é apresentar a novidade musical: "Primeiro } \\
\text { na 89" é o seu slogan. } \\
\text { - Abertura para a produção local em caso de participação em } \\
\text { promoção da emissora. } \\
\text { Eventos: } \\
\text { - Sua equipe conta com um coordenador de promoção, } 10 \\
\text { funcionários fixos e free-lancers que, dependendo do porte da ação } \\
\text { promocional, somam mais de } 20 \text { pessoas acionadas em escolas, } \\
\text { faculdades, boates e bares. } \\
\text { - A emissora organiza eventos musicais com bandas clichê como Jota } \\
\text { Quest, shows do momento, caso do "Cinco Bandas MTV", e ainda } \\
\text { popularescos, como o grupo Babado Novo. }\end{array}$ \\
\hline $\begin{array}{l}\text { Rede } \\
\text { Evangélica } \\
\text { Maranatha }\end{array}$ & $\begin{array}{l}\text { MARANATA } \\
106.1\end{array}$ & $\begin{array}{l}\text { - A relação com os eventos aqui é basicamente com os organizados } \\
\text { pela igreja, tais quais encontros, congressos, retiros e cultos. }\end{array}$ \\
\hline $\begin{array}{l}\text { Prefeitura } \\
\text { Municipal de } \\
\text { Campinas }\end{array}$ & $\begin{array}{l}\text { RÁDIO } \\
\text { EDUCATIVA } \\
101.9\end{array}$ & $\begin{array}{l}\text { - Programação: variada dentro do segmento adulto. Abertura para a } \\
\text { produção local. } \\
\text { - Eventos musicais: Por se tratar de uma emissora da Prefeitura } \\
\text { Municipal, divulga eventos organizados pela Secretaria Municipal de } \\
\text { Cultura. }\end{array}$ \\
\hline
\end{tabular}

Fonte: autoria própria. 


\section{Tabela 1}

\begin{tabular}{|c|c|c|c|}
\hline \multicolumn{4}{|c|}{ Promoções da Rede Jovem Pan (custo para o anunciante - 2008) } \\
\hline Tipo de Promoção & Duração & | Inserções na programação & Preço R\$ \\
\hline $\begin{array}{l}\text { - Veículo promocional: "circula nos } \\
\text { principais pontos da cidade, ou num único } \\
\text { ponto. O veículo inclui um locutor e duas } \\
\text { modelos que distribuem brindes, os quais } \\
\text { podem ser do cliente ou não". }\end{array}$ & 3 horas & $\begin{array}{l}6 \text { flashes ao vivo de } 60 " \\
\text { (sessenta segundos). }\end{array}$ & $3.300,00$ \\
\hline $\begin{array}{l}\text { - Ação promocional: "Realizada em local a } \\
\text { ser escolhido pelo cliente, com dj, } \\
\text { equipamento de som e duas promotoras". }\end{array}$ & 4 horas & $\begin{array}{llr}6 \text { flashes gravados de } & 30 " \\
\text { (trinta segundos) er } & 20 \\
\text { inserções de } 10 " & \text { (dez } \\
\text { segundos) comunicando } & 0 \\
\text { evento. } & & \end{array}$ & $2.378,00$ \\
\hline
\end{tabular}

Fonte: material promocional da Rede Jovem Pan. 
ESPAÇO E CULTURA, UERJ, RJ, N. 30, P.65-79, JUL./DEZ. DE 2011 http://www.e-publicacoes.uerj.br/index.php/espacoecultura/ 